\title{
Thymic Tumor pT0 TNM Finding v8
}

National Cancer Institute

\section{Source}

National Cancer Institute. Thymic Tumor pTO TNM Finding v8. NCI Thesaurus. Code

C136307.

Thymic tumor without evidence of primary tumor. (from AJCC 8th Ed.) 